\title{
Assessment of Awareness of Diabetic Retinopathy among patients with Diabetes Mellitus attending the endocrine clinic at Jordan University Hospital
}

\author{
Bahaeddin A El Khatib ${ }^{1}$, Hussam H AlHawari ${ }^{2 *}$ and Muawyah D Al Bdour ${ }^{2}$ \\ ${ }^{1}$ Michigan State University, College of Human Medicine, East Lansing, Michigan, USA \\ ${ }^{2}$ Department of Internal Medicine, Faculty of Medicine, The University of Jordan, Amman, Jordan
}

\section{Article Info}

*Corresponding author:
Hussam H AlHawari
Department of Internal Medicine
Faculty of Medicine
The University of Jordan
P.O. Box 13046
Amman $11942-$ Jordan
Tel: +962799651232
E-mail: h.hawari@ju.edu.jo

Received: April 3, 2017

Accepted: April 10, 2017

Published: April 15,2017

Citation: El Khatib BA, AlHawari $\mathrm{HH}, \mathrm{Al}$ Bdour MD. Assessment of Awareness of Diabetic Retinopathy among patients with Diabetes Mellitus attending the endocrine clinic at Jordan University Hospital. Madridge J Ophthalmol. 2017; 2(1): 17-21.

doi: 10.18689/mjop-1000106

Copyright: (c) 2017 The Author(s). This work is licensed under a Creative Commons Attribution 4.0 International License, which permits unrestricted use, distribution, and reproduction in any medium, provided the original work is properly cited.

Published by Madridge Publishers

\begin{abstract}
Aim: To assess the degree of diabetic patients' awareness about diabetic retinopathy and their action toward having screening tests and follow up visits.
\end{abstract}

Methods: Diabetic patients who attended the diabetes clinic at Jordan University Hospital were administered a questionnaire in order to assess their awareness of diabetic retinopathy and the need to do a routine screening and follow up care for this disease.

Results: A total of 115 patients were included in the study. of the enrolled patients; 58 were males $(50.4 \%)$. The vast majority of patients enrolled believed that; diabetes could affect their eyes (98.3\%), controlling their blood sugar levels can help preserve their vision (98.3\%), and that diabetes can lead to blindness (99.1\%). However, only about half of the surveyed patients claimed to be familiar with diabetic retinopathy (50.4\%). When asked if it was important for diabetics to have their eyes checked annually, the majority answered yes (90.4\%). In contrast, less than half of the patients reported getting their eyes checked annually (38.3\%). When asked about barriers preventing the patients from getting eye screening, lack of knowledge about diabetic retinopathy scored the highest (33.9\%), in line with the relative lack of familiarity of these patients with diabetic retinopathy.

Conclusion: Although most of the subjects of this study knew that diabetes mellitus can affect the eye and that better control of diabetes mellitus can prevent or delay the onset of $D R$, there was significant discordance between that knowledge and having appropriate screening and management of DR. These findings emphasize the need for increasing the awareness of diabetic retinopathy amongst Jordanian diabetics and the importance of annual ophthalmic eye screening.

Keywords: Awareness; Diabetes mellitus; Diabetic retinopathy; Eye screening.

\section{Introduction}

As with the rest of the globe, the incidence and prevalence of diabetes in Jordan has been increasing at an alarming rate. Diabetes-associated mortality is now ranked as the fourth most common cause of death in Jordan [1]. Both the Diabetes Control and Complications Trial (DCCT) and the United Kingdom Prospective Diabetes Study (UKPDS) showed that intensive glycemic control reduces the incidence and progression of micro-vascular complications (retinopathy, nephropathy and neuropathy) in type 1 and type 2 diabetes[2,3]. A recent study done on Turkish diabetic patients showed that although most 
patients knew that diabetes could lead to eye complications, very few patients were aware of the need to have regular eye examinations and better diabetes control in order to prevent these complications [4].

Diabetic retinopathy (DR) is the leading cause of new onset blindness worldwide. It is estimated that by 2030, the number of people globally with DR will increase to 191.0 million, compared to 126.6 million in 2010 [5]. World Health Organization (WHO) aims to stimulate and support the adoption of effective measures for the surveillance, prevention and control of diabetes and its complications, particularly in low and middle-income countries [6]. As a part of this, WHO conducts surveillance of diabetes and its risk factors and also started to celebrate the World Diabetes Day (November the $14^{\text {th }}$ of each year); to build awareness on the global epidemic of diabetes [6]. It is critical for physicians and patients alike to be aware of this debilitating disease and focus their efforts on awareness, screening and prevention. A rigorous study of the knowledge of DR among Jordanian diabetics has not been done. In this study, a questionnaire was administered to Jordanian diabetics to assess their awareness of diabetic retinopathy, and the importance of screening and glucose control in this disease.

\section{Subjects and Methods}

The study was approved by the Institutional Review Board (IRB) at Jordan University Hospital. The study participants were seen at Jordan University Hospital Endocrinology clinic, inclusion criteria were diabetic patients above the age of 18 and patients with type 1 and type 2 Diabetes. Exclusion criteria were health care professionals with diabetes and patients diagnosed and/or previously treated in an eye clinic for diabetic retinopathy.

After a written informed consent was obtained, a diabetic retinopathy (DR) awareness questionnaire was administered by a physician to the patients who were invited to participate in the study. Participation was of no cost and participants did not receive any stipends.

The DR awareness questionnaire consisted of 15 questions and four parts (Table 2). The questionnaire was created by the researchers conducting the study and validated for use by the University of Jordan Faculty of Medicine. Selected questions used in a previously published Turkish study in addition to further questions added by the researchers were used to create the questionnaire ${ }^{4}$. The first section of the questionnaire included questions in regards to patient demographics in terms of age, sex, education level and duration of DM. Table 2 list the patient demographics in regards to the aforementioned subject matters. The second section of the questionnaire included questions assessing patient's knowledge about DM and vision. The following questions were asked; do you believe that diabetes can affect your eyes? Do you believe that controlling your blood sugar levels can help preserve your vision? Do you believe that diabetes can lead to blindness?
Table 1. Diabetic retinopathy awareness survey

\begin{tabular}{|c|c|c|}
\hline S.No & Details & Survey Report \\
\hline 1 & Name & \\
\hline 2 & Age & \\
\hline 3 & Sex & Male / Female \\
\hline 4 & Occupation & \\
\hline 5 & Level of Education & $\begin{array}{l}\text { Elementary/ } \\
\text { Preparatory/Secondary/ } \\
\text { Community college/ } \\
\text { University/Higher }\end{array}$ \\
\hline 6 & Are you a diabetic? & Yes/No \\
\hline 7 & Date of diagnosis? & \\
\hline 8 & $\begin{array}{l}\text { Do you believe that Diabetes can affect your } \\
\text { eyes? }\end{array}$ & Yes/No \\
\hline 9 & $\begin{array}{l}\text { Do you believe that controlling your blood } \\
\text { sugar can help preserve your vision? }\end{array}$ & Yes/No \\
\hline 10 & $\begin{array}{l}\text { Do you believe that Diabetes can lead to } \\
\text { blindness? }\end{array}$ & Yes/No \\
\hline \multirow[t]{2}{*}{11} & Do you know what diabetic retinopathy is? & Yes/No \\
\hline & $\begin{array}{l}\text { a. If you answered yes to the previous } \\
\text { question, how did you become familiar } \\
\text { with diabetic retinopathy? }\end{array}$ & $\begin{array}{l}\text { Media/Doctor/Eye } \\
\text { Doctor/Reading/Other }\end{array}$ \\
\hline 12 & Do you have diabetic retinopathy? & Yes/ No/ Not sure \\
\hline 13 & $\begin{array}{l}\text { Do you think it is important for a diabetic to } \\
\text { check their eyes annually? }\end{array}$ & Yes/No \\
\hline 14 & Do you check your eyes annually? & Yes/No \\
\hline 15 & $\begin{array}{l}\text { On a scale of } 1-10 \text { how happy would you say } \\
\text { you are with your knowledge about } \\
\text { Diabetes? }(1-10)\end{array}$ & $\begin{array}{l}\text { Diabetic retinopathy? } \\
(1-10)\end{array}$ \\
\hline 16 & $\begin{array}{l}\text { What do you think was the biggest barrier for } \\
\text { not getting eye screening? }\end{array}$ & $\begin{array}{l}\text { Lack of knowledge about } \\
\text { diabetic retinopathy } \\
\text { Lack of access to eye } \\
\text { care } \\
\text { Cost/Insurance } \\
\text { Fear of discovery } \\
\end{array}$ \\
\hline
\end{tabular}

Table 2: Patient demographics in regards to age, sex, education level and duration of diabetes mellitus.

\begin{tabular}{lll}
\hline Age & $\mathrm{N}=115$ & $\%$ \\
\hline 18-40 years old & 28 (females 14, males 14) & 24.3 \\
$51-60$ years old & 48 (females 29, males 19) & 41.7 \\
$>60$ years old & 39 (females 14, males 25) & 33.9 \\
\hline Sex & $\mathrm{N}=115$ & $\%$ \\
\hline Male & 58 & 50.4 \\
Female & 57 & 49.6 \\
\hline Education level & $\mathrm{N}=115$ & $\%$ \\
\hline Elementary and preparatory & 47 & 40.9 \\
Secondary and community college & 37 & 32.2 \\
University degree and higher & 31 & 27.0 \\
\hline Duration of diabetes & $\mathrm{N}=115$ & $\%$ \\
\hline$<5$ years & 47 & 40.9 \\
$5-10$ years & 21 & 18.2 \\
$>10$ years & 47 & 40.9 \\
\hline
\end{tabular}

The third section of the questionnaire included questions assessing patient's awareness of DR and annual eye examinations. The following questions were asked; do you know what diabetic retinopathy is? How did you become familiar with diabetic retinopathy? Do you think it is important for diabetics to check their eyes annually? Do you check your eyes annually?

The fourth and final section of the questionnaire included questions that inquired about how content the patient is with their knowledge of DM and DR, and what they thought the biggest barrier was for preventing them from getting their eyes screened. The following questions were asked; on a scale 
of 1-10 (1 being the least and 10 being the greatest) how happy would you say you are with your knowledge about: Diabetes? Diabetic retinopathy? What do you think is the biggest barrier for not getting your eyes screened?

The questionnaire was self-administered; however, there was always an attending physician and/or a medical resident available with the patient to assist them in filling out the questionnaire or answering any questions or concerns. We made sure all the participating patients were fully aware of the study and its aims before giving their consent to participate in the study. A total of 115 patients were enrolled in the study.

Data analysis: Data was collected from questionnaires and presented as percentages.

\section{Results}

A total of 125 patients were offered the opportunity to participate in the study, while 115 patients agreed to enroll (92\%). of the enrolled patients; 58 were males (50.4\%) and 57 were females (49.6\%). The age groups were divided into 3 categories: $18-50$ years old ( $N=28 ; 14$ females and 14 males), 51-60 years old ( $\mathrm{N}=48 ; 29$ females and 19 males) and above 60 years old ( $\mathrm{N}=39 ; 14$ females and 25 males). The highest achieved education level of the patients was divided into 3 categories as well: Elementary or preparatory school $(\mathrm{N}=47)$, secondary school or community college $(\mathrm{N}=37)$ and university degree or higher $(\mathrm{N}=31)$. The duration of diabetes amongst the patients was: less than 5 years $(N=47), 5-10$ years $(N=21)$ and more than 10 years $(\mathrm{N}=47)$

Table 3 below shows the results of assessing patient's knowledge on the association between diabetes and vision. The vast majority of patients enrolled believed that; diabetes could affect their eyes ( $N=113,98.3 \%)$, controlling their blood sugar levels can help preserve their vision $(N=113,98.3 \%)$, and that diabetes can lead to blindness ( $N=114,99.1 \%)$.

Table 3: Questions assessing patients' knowledge in regards to the association between diabetes mellitus and vision.

\begin{tabular}{lll}
\hline & $\mathrm{N}=115$ & $\%$ \\
\hline Do you believe that diabetes can affect your eyes? & & \\
$\quad$ Yes & 113 & 98.3 \\
No & 2 & 1.7 \\
$\begin{array}{l}\text { Do you believe that controlling your blood sugar can } \\
\text { help preserve your vision? }\end{array}$ & & \\
$\quad$ Yes & 113 & 98.3 \\
No & 2 & 1.7 \\
Do you believe that diabetes can lead to blindness? & & \\
$\quad$ Yes & 114 & 99.1 \\
No & 1 & 0.9 \\
\hline
\end{tabular}

However, in regards to patient's awareness of diabetic retinopathy only about half claimed to be familiar with diabetic retinopathy $(\mathrm{N}=58,50.4 \%)$. of those 58 patients who claimed knowledge of diabetic retinopathy, the various methods of how they became familiar with diabetic retinopathy were as follows: Media $(\mathrm{N}=8,13.8 \%)$, primary care physician or endocrinologist ( $N=11,19.0 \%)$, ophthalmologist $(N=5,8.6 \%)$, individual reading education ( $N=9,15.5 \%)$, and other $(N=25$, 43.1\%). Table 4 summarizes these results.
Table 4: Questions assessing how patients became familiar with diabetic retinopathy

\begin{tabular}{lll}
\hline & $\mathrm{N}=58$ & $\%$ \\
\hline Media & 8 & 13.8 \\
Primary care physician /Endocrinologist & 11 & 19.0 \\
Ophthalmologist & 5 & 8.6 \\
Self-learning/ reading & 9 & 15.5 \\
Other & 25 & 43.1 \\
\hline
\end{tabular}

When asked if it was important for diabetics to have their eyes checked annually, the majority answered yes $(N=104$, 90.4\%). Unfortunately, however less than half of the patients get their eyes checked annually ( $N=44,38.3 \%)$. When asked about barriers preventing the patients from getting eye screening the results were; lack of knowledge about diabetic retinopathy $(\mathrm{N}=39,33.9 \%)$, lack of access to eye care $(\mathrm{N}=12$, $10.4 \%)$, cost/ insurance $(\mathrm{N}=19,16.5 \%)$, fear of discovery $(\mathrm{N}=14,12.2 \%)$, two or more of the factors mentioned above $(N=6,5.2 \%)$, none $(N=20,17.4 \%)$, other $(N=5,4.3 \%)$. Table 5 summarizes these results. On a scale of 1-10, the patients were asked how happy they were with their knowledge about diabetes and diabetic retinopathy, $40.9 \%(\mathrm{~N}=47)$ were on the scale of less than 6 in regards to their knowledge about diabetes and $35.7 \%(\mathrm{~N}=41)$ were on the scale of less 6 in regards to their knowledge about diabetic retinopathy.

Table 5: Barriers preventing diabetic patients from getting eye screening.

\begin{tabular}{lll}
\hline & $\mathrm{N}=115$ & $\%$ \\
\hline Lack of knowledge about diabetic retinopathy & 39 & 33.9 \\
Lack of access to eye care & 12 & 10.4 \\
Cost/ Insurance & 19 & 16.5 \\
Fear of discovery & 14 & 12.2 \\
Two or more of the factors mentioned above & 6 & 5.2 \\
None & 20 & 17.4 \\
Other & 5 & 4.3 \\
\hline
\end{tabular}

\section{Discussion}

The Hashemite Kingdom of Jordan is located in the Middle East, with a total land area of $89,318 \mathrm{Km}^{2}$, and a population size of $6,675,0007$ [7]. The prevalence of diabetes in Jordan was about $17.1 \%$ in 2008 [8]; this has increased to 28.6\% in 2012 [9]. This shows a significant and an alarming increase in the prevalence of diabetes in Jordan. A large prospective study done at Jordan University Hospital in 2007 included a total of 1961 patients, showed a prevalence of diabetic retinopathy of $64.1 \%$ [10], another study showed a relatively lower incidence of diabetic retinopathy in Jordanians with newly diagnosed diabetes but in those with retinopathy, the prevalence of vision threatening maculopathy was high [11]. In addition, Diabetic retinopathy and glaucoma were the leading causes of severe bilateral blindness in Jordan $[12,13]$. Per another study done in northern Jordan, cataract and diabetic retinopathy were the two major causes of blindness and visual impairment [10]. Comparing our numbers with the Middle-East and North Africa (MENA) region, the current prevalence of diabetes in adults in MENA region is estimated to be around 9.2\% in 2013 [14]. The prevalence of DR in some regional countries was less than our prevalence of $64.1 \%$ but is still relatively high [15], for example, in UAE, the prevalence 
of DR was $54.2 \%$ in 2007 [16], in Kuwait, it was $40.0 \%$ in 2007 [17], and in Egypt it was $20.5 \%$ in 2010 [18]. All of the above studies and multiple other similar studies showed that the prevalence of diabetes has increased globally and so the cases of diabetic retinopathy.

Our study showed that most of the participant diabetic patients were aware that diabetes could affect their eyes, $98.3 \%$, and that controlling blood sugar levels can help preserve vision, $98.3 \%$. The vast majority of the patients were also aware that diabetes could lead to blindness, $99.1 \%$. However, only around half of the patients claimed to be familiar or aware of diabetic retinopathy, 50.4\%.

Interestingly, $90.4 \%$ of the patients believed that it was important for diabetics to get their eyes checked annually while only less than half of the patients, $38.3 \%$, have actually underwent an eye examination within the last year. Similarly in a study done in Myanmar by Muecke et al. they found that although $90.4 \%$ of the diabetic patients in their study believed that they should have eye examinations on a regular basis, only $57 \%$ had seen an ophthalmologist for an eye exam [19]. Likewise, a study done in Japan by Funatsu et al. showed that although more than $98 \%$ of the patients were of aware of diabetes association with eye disease, only $69.5 \%$ underwent annual eye examinations [20].

When we asked our patients what the greatest barrier was for not receiving an annual eye examination, the response with the greatest percentage, 33.9\%, was lack of awareness and knowledge about diabetic retinopathy. This finding mirrors the results of a study done in Ireland by Dervan et al. which concluded that the main barrier to receiving adequate eye screening amongst diabetics was the lack of knowledge in regards to the need for ocular examinations [21].

When we asked our patients who were familiar and aware of diabetic retinopathy, $50.4 \%$ of them were familiar and aware of $D R$, by specifying the means of how they became familiar with diabetic retinopathy, of the listed methods either than "other" the highest percentage was through "primary care physician or endocrinologist", $19.0 \%$. This result also mirrors Dervan et al. finding that the most significant predictor for receiving eye screening was a previous physician recommendation about the necessity of regular eye examinations [21]. Surprisingly, only $8.6 \%$ of our patients became familiar with DR from their ophthalmologist, and probably they consulted their ophthalmologist for a different issue.

The results of our study illustrate that although the majority of diabetic patients being treated at Jordan University Hospital are aware of the importance of annual eye examinations and despite having a universal access to eye health in Jordan as per the National Eye Health Plan in Jordan, a minority embark on receiving annual eye examinations. We have also found that the greatest barrier for receiving eye screening was the lack of knowledge and awareness of diabetic retinopathy amongst the patients; while those who were aware of diabetic retinopathy came to do so through their primary care physician or endocrinologist. This exemplifies the importance of patient education and physician education on the need for annual eye examinations amongst diabetics and the continued effort of diabetic retinopathy awareness in the medical profession.

Our study found that although $98.3 \%$ of patients were aware that diabetes can damage their eyes and controlling their blood sugar levels can help preserve their vision, only $50.4 \%$ claimed to be familiar or aware of diabetic retinopathy. Additional, while $90.4 \%$ of patients believed that it was important for diabetics to get their eyes checked annually, only $38.3 \%$ have undergone an eye examination within the past year. This emphasizes the need for increasing the awareness of diabetic retinopathy amongst Jordanian diabetics and the importance of annual ophthalmic eye screening.

Conflicts of interest: The author reported the conflict of interest statement.

\section{References}

1. The Centers for Disease Control and Prevention (CDC) in Jordan. Fact sheet. November 2013.

2. The Effect of Intensive Treatment of Diabetes on the Development and Progression of Long-Term Complications in Insulin-Dependent Diabetics Mellitus. The Diabetes Control and Complications Trial Research Group. N Engl J Med. 1993; 329(14):977-86. doi:10.1056/NEJM199309303291401

3. King P, Peacock I, Donnelly R. The UK Prospective Diabetes Study (UKPDS): clinical and therapeutic implications for type 2 diabetes. Br J Clin Pharmacol. 1999; 48(5): 643-648. doi: 10.1046/j.1365-2125.1999.00092.x

4. Cetin EN, Zencir M, Fenkci S, Akin F, Yildirim C. Assessment of awareness of diabetic retinopathy and utilization of eye care services among Turkish Diabetic Patients. Prim Care Diabetes. 2013; 7(4): 297-302. doi:10.1016/j.pcd.2013.04.002

5. Zheng $\mathrm{Y}, \mathrm{He} \mathrm{M}$, Congdon N. The worldwide epidemic of diabetic retinopathy. Indian J Ophthalmol. 2012; 60(5): 428-431. doi: 10.4103/0301-4738.100542.

6. World Health Organization (WHO). Diabetes Fact Sheets. 2013 September 12, 2012; Available from: http://www.who.int/mediacentre/ factsheets/fs312/ed/index.html.

7. Jordan in Figures, 2014. http://dos.gov.jo/dos_home_e/main/linkedhtml/jordan_no.htm. Department of Statistics, Jordan.

8. Ajlouni K1, Khader YS, Batieha A, Ajlouni H, El-Khateeb M. An increase in prevalence of diabetes mellitus in Jordan over 10 years. J Diabetes Complications. 2008; 22(5):317-24.doi:10.1016/j.jdiacomp.2007.01.004.

9. Rabiu MM, Al Bdour MD, Abu Ameerh MA, Jadoon MZ. Prevalence of blindness and diabetic retinopathy in northern Jordan. Eur J Ophthalmol. 2015; 25(4):320-7. doi: 10.5301/ejo.5000557.

10. Al-Bdour MD, Al Till MI, Abu Samra K. Risk Factors for Diabetic Retinopathy among Jordanian Diabetics. Middle East Afr J Ophthal. 2008; 15(2):77-80. doi: 10.4103/0974-9233.51997.

11. Jammal $H$, Khader $Y$, Alkhatib S, Abujbara M, Alomari M, Ajlouni K. Diabetic retinopathy in patients with newly diagnosed type 2 diabetes mellitus in Jordan: prevalence and associated factors. J Diabetes. 2013; 5(2):172-9. doi: 10.1111/1753-0407.

12. Al-Bdour MD, Al-Till MI, Abu-Khader IB. Causes of blindness among adult Jordanians: a hospital-based study. Eur J Ophthalmol. 2002; 12 (1):5-10.

13. Al-Till MI, Al-Bbour MD, Ajlouni KM. Prevalence of blindness and visual impairment among Jordanian diabetics. Eur J Ophthalmol. 2005; 15(1):62-8.

14. Majeed A1, El-Sayed AA, Khoja T, Alshamsan R, Millett C, Rawaf S. Diabetes in the Middle-East and North Africa: an update. Diabetes Res Clin Pract. 2014; 103(2):218-22. doi: 10.1016/j.diabres.2013.11.008. 
15. Khandekar R. Screening and Public Health Strategies for Diabetic Retinopathy in the Eastern Mediterranean Region. Middle East Afr J Ophthalmol. 2012; 19(2):178-184. doi: 10.4103/0974-9233.95245.

16. Saadi H, Carruthers SG, Nagelkerke N, Al-Maskari F, Afandi B, Reed R, et al. Prevalence of diabetes mellitus and its complications in a populationbased sample in Al Ain, United Arab Emirates. Diabetes Res Clin Pract. 2007; 78(3):369-77. doi:10.1016/j.diabres.2007.04.008.

17. Al-Adsani AM. Risk factors for diabetic retinopathy in Kuwaiti type 2 diabetic patients. Saudi Med J. 2007; 28(4):579-83.

18. Macky TA, Khater N, Al-Zamil MA, El Fishawy H, Soliman MM. Epidemiology of diabetic retinopathy in Egypt: a hospital-based study. Ophthalmic Res. 2011; 45(2):73-78. doi: 10.1159/000314876.
19. Muecke JS, Newland HS, Ryan P, Ramsay E et al. Awareness of diabetic eye disease among general practitioners and diabetic patients in Yangon, Myanmar. Clinical and experimental ophthalmology. 2008; 36(3): 265-273. doi: 10.1111/j.1442-9071.2008.01724.x.

20. Funatsu $H$, Hori S, Shimizu E, Nakamura S. Questionnaire survey on periodic ocular examinations in Japanese diabetic patients. American Journal of Ophthalmology. 2003; 136(5): 955-957. doi:10.1016/S00029394(03)00542-7.

21. Dervan E, Lilis D, Flynn L, Staines A, O'Shea D. Factors that influence the patient uptake of diabetic retinopathy screening. Irish Journal of Medical Science. 2008; 177(4): 303-308. doi: 10.1007/s11845-008-0192-5. 